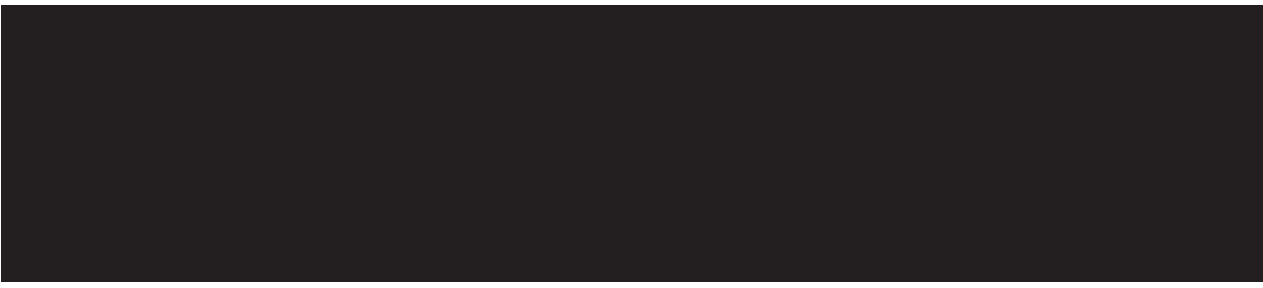

\section{Editor's Message}

2 A Pollmann

\section{Research}

3 Costs and stewardship of laboratory tests in the Capital Health District $R$ Farmer

$8 \quad$ Student use of self-directed learning time in an undergraduate curriculum J Gould, I Arseneau, S Daizel, H Petropolis, K Mann

\section{Review}

13 Pseudomonas aeruginosa wound infections: a critical appraisal of topical antiseptics H Augustine, J Gillis, J Williams

\section{Diagnose This}

18 Red currant jelly, sausages and donuts J Kang, A Dmytriw, M Gundogan

\section{Case Report}

$21 \quad$ A case report of a delayed-interval delivery in a dichorionic diamniotic twin pregnancy J White, C Craig, D Ahn

25 An unusual case of intrathoracic Castleman's Disease

R Schoon, L Mulroy, Z Xu, D Bethune

\section{Humanities}

29 Valuable lessons learned through the "hidden curriculum" of medicine: one student's perspective

NMaclnnis

\section{Book Reviews}

32 Being Mortal - Atul Gawande NCorbett

\section{Editorial Staff 2015}

Editor-in-Chief André Pollmann (Class of 2018)

Editor of Reviews

lan Macdonald (Class of 2017)

Ceilidh MacPhail (Class of 2018)

Leanne Delaney (Class of 2019)

Humanities Editor Jessie Kang (Class of 2016) Jessica Maclntyre (Class of 2019)

\section{Layout Editor}

Mike Butler (Class of 2018)

Web Editor

Chad Purcell (Class of 2019)

Archives Editor Mike Wong (Class of 2014)

\title{
Credits
}

Layout design by Alison Wong

Cover design by Michiko Maruyama

Supported in part by the Dalhousie Medical Student Society

\section{Contact}

DMJ, Box 201, Sir Charles Tupper Medical Building, Dalhousie University Halifax, Nova Scotia, B3H 4R2 dmj@dal.ca http://ojs.library.dal.ca/DMJ

\section{Distribution}

Distributed by Doctors Nova Scotia

All articles published, including editorials, represent the opinions of the authors and do not reflect the policy of the DMJ Editorial Board, Dalhousie University, or the institution with which the author is affiliated, unless this is clearly specified. Neither the members of the Editorial Board of this journal, the publisher, nor Dalhousie University assume any responsibility for errors or omissions in this journal. 